\section{Ocho casas, tres patios Gran Canaria, España}

Un edificio de viviendas de fachada continua y baja altura es pensado como un volumen penetrable por la luz natural. Al interior, se generan tres patios de colores diferentes que hacen ingresar la luz y que permiten caracterizar los recintos. La fachada, por su parte, es dinámica y cambiante, según sus aperturas al contexto.
A low-rise continuous facade residential building is thought as a volume penetrated by natural light. Three interior light patios of different colors that bring light to the interior and characterize the spaces. The facade, for its part, is dynamic and changing according to its openings towards the context.

Pedro Romera Profesor, Universidad de Las Palmas de Gran Canaria Ángela Ruiz Profesora, Universidad de Las Palmas de Gran Canaria Fotografía Jorge Hernández, Juan Correa
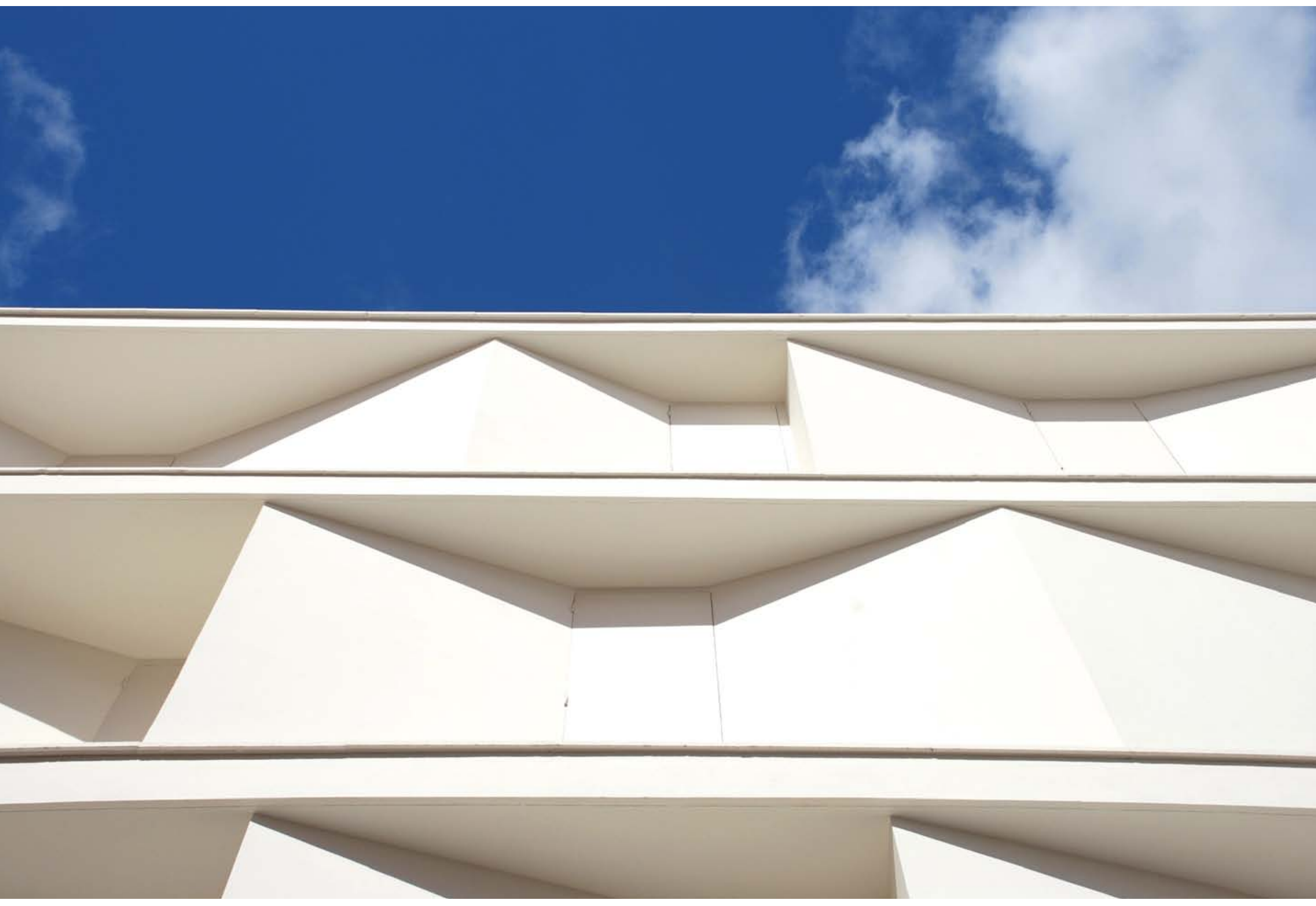

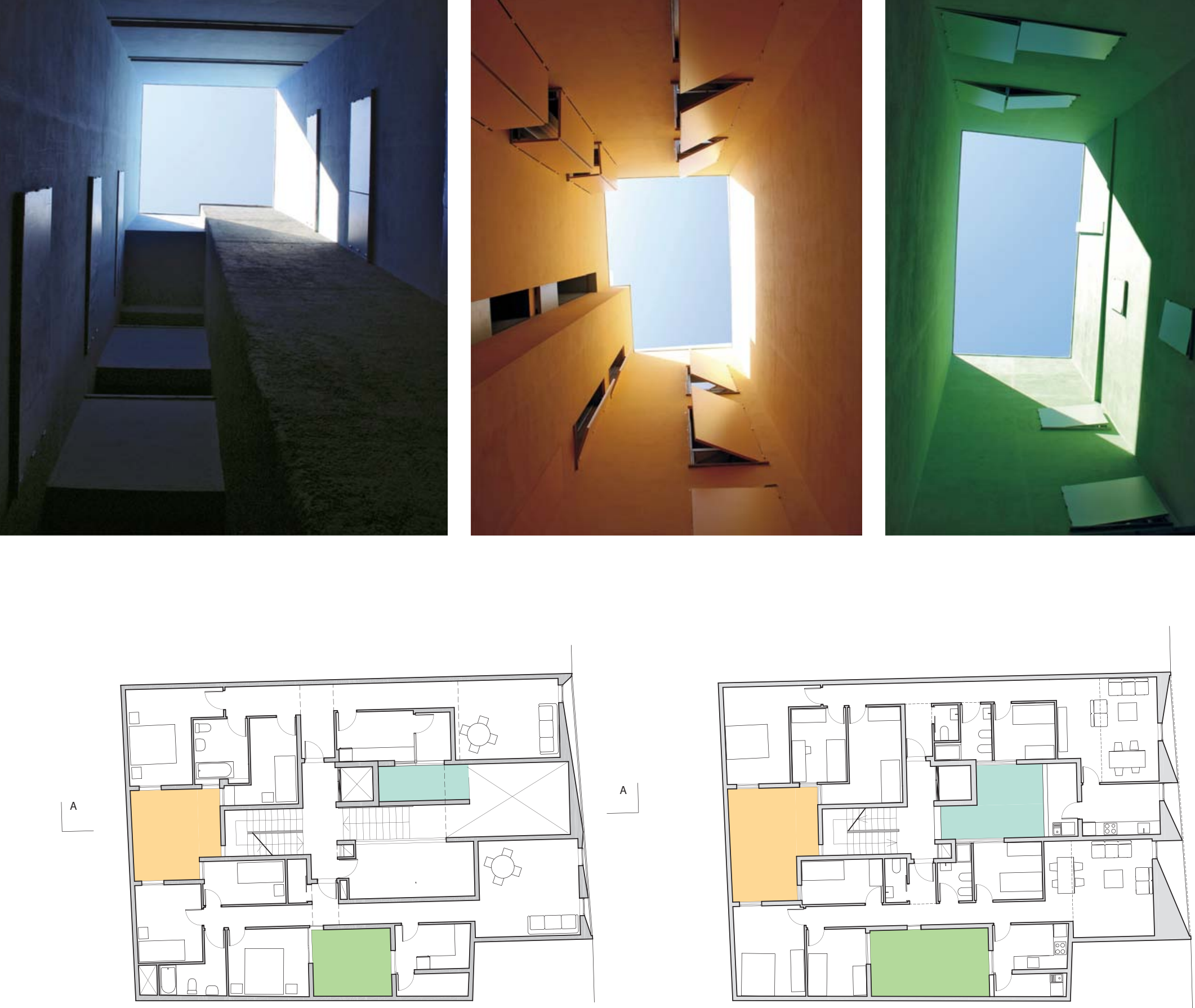

PLANTA NIVEL $+1.50 \mathrm{~m} \quad$ E $1: 250$

PLANTA NIVEL $+4.50 \mathrm{~m}$ y superiores
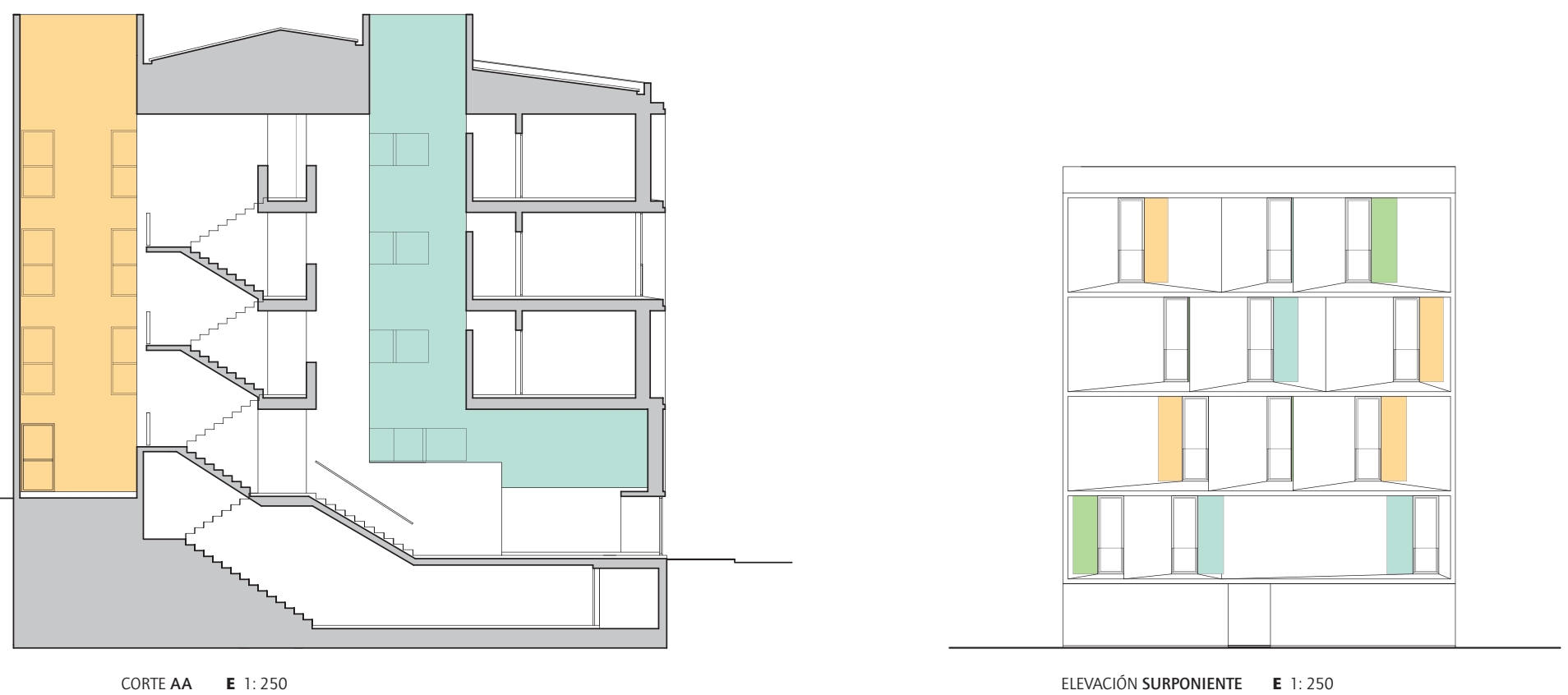

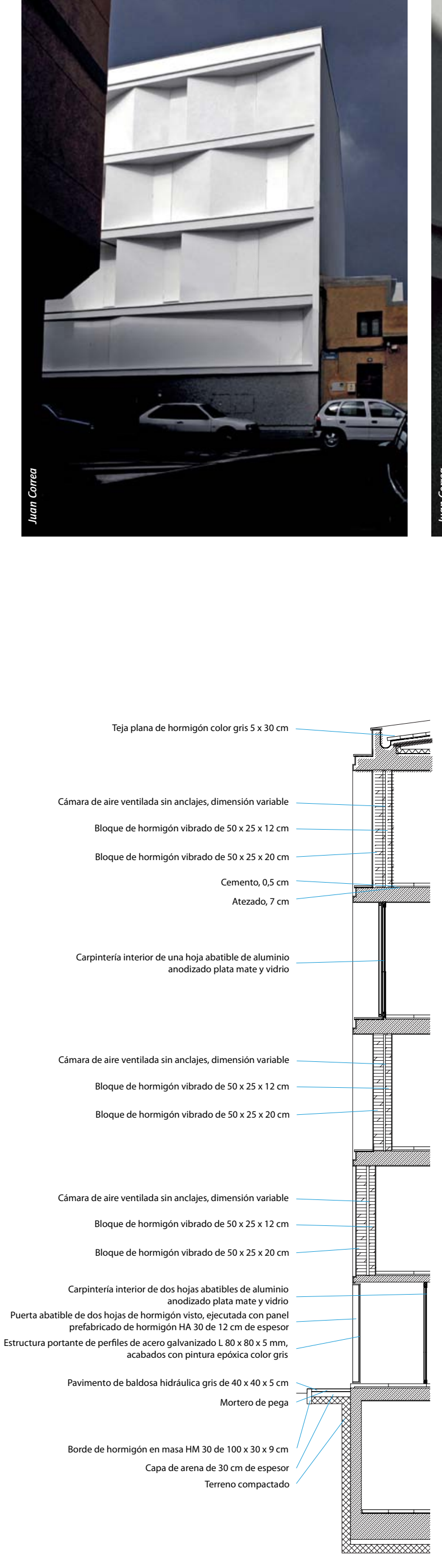

OCHO CASAS, TRES PATIOS

Arquitectos Pedro Romera, Ángela Ruiz

Colaboradores Jorge Hernández, Laura Gómez, Gwendolyn Méndez Ubicación Santa Lucía de Tirajana, Gran Canaria, España

Cliente Instituto Canario de la Vivienda, Gobierno de Canarias Cálculo estructural Manuel Hernández

Construcción Construcciones Rodríguez Luján S.L.

Ingeniero Industrial CQ Ingenieros y Asociados

Telecomunicaciones Pedro M. Sánchez

Materialidad estructura de muros con cámara ventilada en bloques de hormigón vibrado de 50×25×12 cm, muros interiores y losas de hormigón armado, revestimiento exterior en enlucido de escayola de $1,5 \mathrm{~cm}$ de espesor y acabado en pintura plástica mate, revestimiento interior en estuco de cemento y arena de $1,5 \mathrm{~cm}$ de espesor acabado en pintura látex acrovinílica, persianas exteriores abatibles en placas de alta resistencia

Presupuesto $19 \mathrm{uf} / \mathrm{m}^{2}$ (US\$ 817/ $\left.\mathrm{m}^{2}\right)$

Superficie terreno $281 \mathrm{~m}^{2}$

Superficie construida $897 \mathrm{~m}^{2}$

Año proyecto 2004

Año construcción 2007 